\title{
How do urban residents use energy for winter heating at home? A large-scale survey in the hot summer and cold winter climate zone in the Yangtze River region
}

Article

Accepted Version

Creative Commons: Attribution-Noncommercial-No Derivative Works 4.0

Jiang, H., Yao, R., Han, S., Du, C., Yu, W., Chen, S., Li, B., Yu, H., Li, N., Peng, J. and Li, B. (2020) How do urban residents use energy for winter heating at home? A large-scale survey in the hot summer and cold winter climate zone in the Yangtze River region. Energy and Buildings, 223. 110131. ISSN 03787788 doi: https://doi.org/10.1016/j.enbuild.2020.110131 Available at https://centaur.reading.ac.uk/91699/

It is advisable to refer to the publisher's version if you intend to cite from the work. See Guidance on citing.

Published version at: http://dx.doi.org/10.1016/j.enbuild.2020.110131

To link to this article DOI: http://dx.doi.org/10.1016/j.enbuild.2020.110131

Publisher: Elsevier

All outputs in CentAUR are protected by Intellectual Property Rights law, including copyright law. Copyright and IPR is retained by the creators or other copyright holders. Terms and conditions for use of this material are defined in the End User Agreement. 


\section{www.reading.ac.uk/centaur}

\section{CentAUR}

Central Archive at the University of Reading

Reading's research outputs online 


\section{Energy and Buildings}

Volume 223, 15 September 2020, 110131

\section{https://doi.org/10.1016/j.enbuild.2020.110131}

\section{How do urban residents use energy for winter heating at home? -A large-scale survey in the hot summer and cold winter climate zone in the Yangtze River Region.}

Haochen Jiang ${ }^{1}$, Runming Yao ${ }^{1,3^{*}}$, Shiyu Han ${ }^{3}$, Chenqiu $\mathrm{Du}^{1,2}$, Wei Yu ${ }^{1,2}$, Shuqin $\mathrm{Chen}^{4}$, Baiyi $\mathrm{Li}^{5}$, Hang $\mathrm{Yu}^{6}$, Nianping $\mathrm{Li}^{7}$, Jinqing Peng ${ }^{7}$, Baizhan $\mathrm{Li}^{1,2^{*}}$

${ }^{1}$ Joint International Research Laboratory of Green Buildings and Built Environments (Ministry of Education), Chongqing University, Chongqing 400045, China

${ }^{2}$ National Centre for International Research of Low-carbon and Green Buildings (Ministry of Science and Technology), Chongqing University, Chongqing 400045, China

${ }^{3}$ School of the Built Environment, University of Reading, Reading RG6 6DF, UK

${ }^{4}$ College of Civil Engineering and Architecture, Zhejiang University, Hangzhou 310058, China;

${ }^{5}$ Faculty of Architecture, Southwest Jiaotong University, Chengdu 610031, China

${ }^{6}$ School of Mechanical Engineering, Tongji University, Shanghai 201804, China;

${ }^{7}$ College of Civil Engineering, Hunan University, Changsha 410082, Hunan, China;

* Corresponding author:

r.yao@ reading.ac.uk;

baizhanli@cqu.edu.cn 


\section{Abstract}

The increased demand for improving indoor thermal environment in the hot summer and cold winter climate zone (HSCW) in the Yangtze River region in China poses enormous challenges in terms of energy policy and design solutions for this unique region. A comprehensive understanding of people's habits and behaviors involving winter heating is imperative for decision making for urban heating infrastructure investment strategies that significantly impact on the decarbonization of heating. However, there has been little knowledge gained from large-scale studies in this region. The aim of this study is to develop a rigorous survey method in order to obtain reliable data for analysis. Five municipal/capital cities across the upper, middle and downstream Yangtze River are surveyed based on 30 randomly generated locations in each city. A total of 8,471 valuable samples were obtained in the survey conducted in the winter from November 2017 to March 2018. It is revealed that air conditioning/air source heat pumps are the predominant systems, accounting for $63 \%$ and $58 \%$ for bedroom and living room heating respectively. The use patterns of heating are diverse featuring 'part-time-part-space' systems in accordance with the occupancy patterns. There is significant evidence of the habit of opening a window to provide a gap for fresh air irrespective of whether the heating is in use. Two-step cluster analysis is employed to subdivide occupants' heating-related behaviors into three clusters to characterize households. This study fills the knowledge gap of winter-heating-related behaviors. The research outcomes will benefit building energy simulations for energy prediction and help policy makers make decisions on providing strategic guidance in terms of winter heating solutions in this region.

\section{Keywords}

Hot summer and cold winter zone; residential buildings; socio-tech survey; winter heating behaviors; 


\section{1. Introduction}

2 Due to its vast territory, China has a diverse climate which has been categorized into five

3 typical climate zones: severe cold, cold, hot summer and cold winter (HSCW), hot summer

4 and warm winter (HSWW) and mild, according to GB50178 [1] for building designs.

5 Arising from China's historical energy policies in the 1950s, the Qinling Mountains -

6 Huaihe River Line (hereafter called the QinHuai Line and denoted as the QH line in this

7 paper) was set up as a geographical boundary to provide distinct heating (northern) and

8 non-heating (southern) regions based on climate conditions (see Figure 1). As a result, in

9 the severe cold and cold zones of northern China, the urban district central heating system

10 has been the most popular mechanism for winter heating and people have been privileged

11 with this heating policy thanks to the urban heating infrastructure and heating incentives.

12 By contrast, the HSCW zone in China shows a typical characteristic of a hot summer and

13 cold winter climate, where the average air temperature in the coldest month is between $0^{\circ} \mathrm{C}$

14 and $10^{\circ} \mathrm{C}$. However, due to the traditional heating division line for northern and southern

15 China, the winter indoor thermal environment in this area is even worse than that in

16 northern China [2]. The average indoor temperature in winter is usually below $10{ }^{\circ} \mathrm{C}$

17 without central space heating facilities [3]. Therefore, space heating in cold winters has

18 been expected to be one of the most necessary measures demanded in order to maintain a

19 basic indoor environmental quality for people's health and wellbeing.

20 The QH boundary heating policy was made mainly due to the economic capacity and

21 energy resource scarcity at the time and it has been challenged by the increased heating

22 demand of the region due to economic reform and growth over the last four decades.

23 Especially, the Yangtze River region accommodates more than 55\% of the population and

24 shares more than $40 \%$ of China's GDP [4]. Thus, it has become one of the well-developed

25 regions of the country. It is not hard to imagine people living in the HSCW climate zone

26 increasing their demand for improved indoor environmental quality [5-8]. However, the

27 national targets pertaining to the cap on primary energy consumption and the peak of $\mathrm{CO}_{2}$

28 emissions have applied specific pressures in this region. Therefore, a trade-off between

29 thermal environment improvement and building energy efficiency is urgently required in 
30 the Yangtze River region, to maintain a healthy growth in energy demand and consumption

31 in buildings.

32 Currently, the question "should district/central heating systems be considered in the HSCW

33 climate zone in China?" has become a hotly debated topic among scholars, policy-makers,

34 and citizens in the region. The issue relates to many factors which could affect the decision

35 making on the investment in urban heating infrastructure from environmental, economic,

36 and social perspectives. There were no detailed policies that could solve the winter heating

37 problems for the HSCW zone. However, for those involved in energy conservation, the

38 fast-growing demand for space heating in the HSCW zone is significantly increasing the

39 national energy consumption, which also causes related problems involving carbon

40 emissions and air pollution. Therefore, in response to this problem, it is necessary to have

41 comprehensive and reliable knowledge of how people use energy for winter heating in their

42 homes, which could be useful for policy recommendations and design guides.

\section{1.1. Literature Review}

44 In the HSCW climate zone, winter heating is an extremely challenging problem due to its 45 complex nature related to the local climate, historical habits, thermal comfort, and socio46 economic, energy and environmental, technical, and occupant behavior issues. To

47 understand the research gap for winter heating in the HSCW zone, a series of previous 48 relevant studies were critically reviewed, as follows.

49 1) The current low level of indoor thermal comfort in winter

50 By reviewing the historical development of the thermal environment in the HSCW zone in 51 China, it can be seen that the level of thermal comfort in winter is at a very low level. Even 52 in recent years, the majority of residential buildings still do not have a full set of winter 53 heating equipment [9]. People in the HSCW zone have lived for many years with no heating.

54 They do not tend to introduce heating devices, but they do put on extra clothes, which has

55 created a local habit of 'enduring the cold winter without heating[10]. 
56 However, this low level of indoor thermal comfort in winter is being rapidly improved due

57 to the rapidly growing economic development in this region. From the study by Wang et

58 al. [11], it is clear that the trend of pursuing better indoor thermal comfort for homes is

59 significantly influencing heating behaviors in the HSCW zone, especially for new

60 generations and the elderly groups. Therefore, it is predicted that the future potential energy

61 consumption for heating in the HSCW zone could be enormous [10], and it is an urgent

62 task to understand the existing winter heating situations in this region and find solutions.

\section{2) Building energy policy}

64 The development of building energy policy in the HSCW zone had a late start and made 65 slow progress. In 2001, the building design standard for the HSCW zone [9] started to 66 raise the issue of the requirement for auxiliary space heating measures for public buildings

67 on cold winter days. Since then, there has been no heating policy relating to residential 68 buildings until the first code [9] was issued in 2010. Disappointingly, there were no detailed

69 policies that could solve the winter heating problems for the HSCW climate zone and the 70 situation remained unchanged until recently. This means in the majority of homes, the poor 71 thermal insulation designs are not well-prepared for space heating [12].

72 Consequently, although the living standard in cold winters in the HSCW region is 73 improving by the increased use of a variety of heating measures, the energy consumed by 74 the diffusion of individual heating devices has also increased incredibly by more than 500 75 times from 1998-2013 [10], which is contrary to the building energy conservation policies 76 for China. Therefore, the question about what would be the appropriate solution for winter 77 heating in this region remains unanswered.

\section{3) Appropriate winter heating systems for HSCW climate}

79 As the demand of winter heating is increasing, the types of heating become an essential 80 concern. Currently, the majority of people living in the HSCW zone who use winter heating, 81 are using individual electrical heating devices or air-conditioners [9]. These individual 82 systems used for space heating are often argued to be inefficient and expensive for energy 
83 due to their low efficiency of performance, and furthermore, because of the poor thermal

84 insulation in the building envelope in this region. By contrast, in northern China, the policy

85 support for district central heating systems has been developed for a long time [13] and has

86 contributed to comfortable indoor environments. Therefore, whether or not to apply the

87 district heating system in the HSCW zone has been argued over for many years on social

88 media and within official civil channels [14, 15].

89 However, many studies have analyzed and provided evidence that it is inappropriate to 90 apply district central heating in the HSCW zone. Studies [7, 13, 16, 17] have suggested

91 that it is unnecessary to provide district heating for southern China. These scholars claim

92 that the proposed development of large scale urban heating infrastructure would obviously

93 burden the country's environmental impact and hinder the progress of energy conservation

94 [18]. It is also discussed that a personalized dispersed heating system is more suitable for

95 the climate conditions of the HSCW zone as there is a much shorter period of heating 96 compared to the severe cold and cold zones. Moreover, Hu et al. [17] state that a dispersed

97 heating system has the advantages of flexibility and easy installation, which does not

98 require huge amounts of engineering work for network refurbishment. As a result, it 99 appears that a dispersed heating system is the appropriate option for winter space heating 100 in the HSCW zone.

101 4) Occupant behaviors using dispersed heating systems

102 Importantly, when using dispersed heating systems, occupants' behaviors become the main 103 controlling factor, but pose many challenges [19]. Many studies [20-22] have verified that 104 occupants' behaviors have a pivotal role in building energy consumption, alongside the

105 thermal performance of building envelopes and the efficiency of heating devices [23-25].

106 Studies have proven that the occupancy profiles, different occupancy patterns, the habit of 107 meeting the demand for fresh air by opening windows [7, 26, 27], and variations in the 108 occupants' thermal preferences for the use time and the temperature setting points of air109 conditioning [28-30] have significant impacts on building energy consumption, along with 110 the usage patterns [22, 23], local diversity[10], and family structure [31]. Therefore, 111 compared to the heating behavior in northern China, the residential heating behaviors in 
112 the HSCW zone are more diverse and complicated in terms of family structure, economic

113 level, thermal comfort requirements, heated room space, and local climate conditions [32].

114 The elucidation of this situation requires further detailed research.

115 Furthermore, it is arguable that many studies of occupancy behaviors and their impact on 116 building energy consumption in this region were simplified and thus of questionable 117 reliability [33]. For example, measurement studies by Lin et al. [10], Yoshino et al. [34], 118 and Wang et al. [8] tested the building operating energy and behaviors, but the sample size 119 was less than 30 households, which could be challenged for varying individual factors. 120 Peng et al. [35] and Ge et al. [36] have studied the energy modeling by combining 121 measurement, simulation, and behavior surveys, but their case studies considered only one 122 city and one type of building. As there were biases in the descriptions of the behaviors, e.g. 123 AC setting points and window operation behavior, the occupant praxeology for winter 124 heating still remains incompletely understood. Thus, with suggestions from statistical 125 modeling in this research field, such as Chen et al. [37] and Guo et al. [25], studies with 126 comprehensive survey data are necessary and essential to understand how people in this 127 region heat their homes and how they behave to secure and maintain this heating.

\section{$128 \quad 1.2$ Aims of the study}

129 Building on the literature above, the aim of this study is to acquire a comprehensive 130 understanding of occupants' heating-related behaviors in residential buildings and their 131 demand for heating in winter in the HSCW region. This study contributes to a rigorous 132 large-scale survey of heating demand in terms of identifying locations, sample size, and 133 questionnaire design. The research outcomes are expected to benefit building energy

134 simulations related to occupant behaviors, policy makers and their decision making, and 135 those requiring strategic guidance on producing winter heating solutions in the HSCW 136 region. This fills the knowledge gap arising from the lack of reliable data on how urban 137 residents in the Yangtze River region use energy for winter heating.

\section{2. Method}


139 Among many methods applying social science to human behavior studies, survey methods

140 such as a census, interviews, and polling are widely considered to be efficient ways of 141 collecting preferences, opinions, behaviors, and factual information [38]. The 142 questionnaire survey method has been applied in this study. The extensive information 143 related to building construction, indoor occupancy, occupant behaviors, and the use of 144 heating devices was considered. The detailed processes involved in the questionnaire 145 design, the selection of the cities, and the sample collection and analysis are described in 146 the following sections.

\section{$147 \quad 2.1$ Selection of cities}

148 To understand the heating situations and occupant behaviors in residential buildings in the 149 HSCW region, five municipality/capital cities - Chongqing, Chengdu, Changsha, 150 Hangzhou, and Shanghai - spread over the upper, middle and lower parts of the Yangtze 151 River, were selected, as shown in Figure 1.

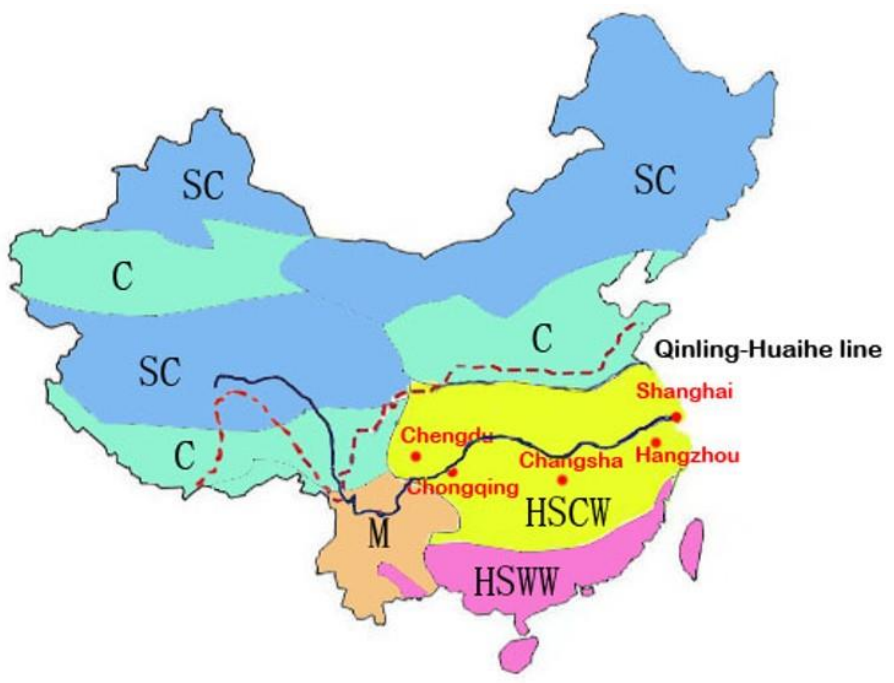

Figure 1: Geographic distribution of the five selected cities in the HSCW zone

155 Detailed climate data for the five cities in this region are listed in Table 1, which were 156 referred to Ref.[39]. It is clearly seen that the five cities share a similar longitude. This 157 leads to a similar annual average air temperature, with a slight range from $16.6^{\circ} \mathrm{C}$ to $18.5^{\circ} \mathrm{C}$. 
158 In addition, Table 1 shows that the annual average relative humidity for the five cities is

159 high at around $75 \%-80 \%$, reflecting the characteristic high air humidity in this region.

160 Table 1: Geographic information and typical meteorological data of the five cities

\begin{tabular}{cccccccc}
\hline City & Latitude & Longitude & $\begin{array}{c}\text { Altitude } \\
(\mathrm{m})\end{array}$ & $\begin{array}{c}\text { Annual } \\
\text { average } \\
\text { temp }\left({ }^{\circ} \mathrm{C}\right)\end{array}$ & $\begin{array}{c}\text { Annual average } \\
\text { RH } \\
(\%)\end{array}$ & $\begin{array}{c}\text { Annual average } \\
\text { radiation } \\
(\mathrm{W} / \mathrm{m} 2)\end{array}$ & $\begin{array}{c}\text { Annual } \\
\text { average } \\
\text { outdoor wind } \\
(\mathrm{m} / \mathrm{s})\end{array}$ \\
\hline Chengdu & 103.52 & 30.45 & 547.7 & 16.6 & 80.97 & 46.60 & 1.19 \\
Chongqing & 106.28 & 29.35 & 259.1 & 18.5 & 81.54 & 42.42 & 1.45 \\
Changsha & 112.55 & 28.13 & 68.0 & 17.1 & 82.24 & 81.06 & 2.14 \\
Hangzhou & 120.10 & 30.14 & 41.7 & 17.0 & 75.79 & 91.33 & 2.07 \\
Shanghai & 121.27 & 31.24 & 5.5 & 16.7 & 75.96 & 107.02 & 3.25 \\
\hline
\end{tabular}

161

\section{$162 \quad 2.2$ Sample sizes}

163 When using the survey method, it is important to obtain a representative sample from a 164 population by using simple random, stratified random, or cluster sampling methods [40].

165 An appropriate sample size determines significantly whether the survey results can truly 166 cover a wide range of situations. To represent the real situations in each city, the cluster 167 sampling method based on probability sampling (i.e. random sampling) was selected. The 168 sample size was determined by using Equation (1) [41].

$$
\mathrm{n}=\frac{\mathrm{X}^{2} \times \mathrm{N} * \mathrm{P} *(1-\mathrm{P})}{\left(\mathrm{ME}^{2} *(\mathrm{~N}-1)\right)+\left(\mathrm{X}^{2} * \mathrm{P} *(1-\mathrm{P})\right)}
$$

170 Where,

$171 \mathrm{n}$----the sample size;

$172 \quad \mathrm{X}^{2}$----the statistical values associated with the desired level of confidence;

173 N----the population size in each city;

174 P----the preliminary estimate of the proportion in the population;

175 ME----the desired margin of error (\%). 
176 In order to determine a sample size of $\mathrm{n}$, a 95\% confidence level is used (Confidence

177 Interval $\mathrm{CI}=0.95$ ) in this study; $\mathrm{ME}$ is set at $5 \%$. For a degree of freedom of 1 , the $\mathrm{X}^{2}$ value

178 can be found using the chi-square test making the value of $X^{2}$ for a $95 \%$ confidence interval

179 (CI) equal to 3.84. According to Ref. [41], as the value of $\mathrm{P}$ was not known, the maximum

180 value of 0.5 was assumed in this study. Based on the census data [4], the population of each

181 city is listed in Table 2. Therefore, the required sample size calculated using Equation (1)

182 is listed in Table 2.

183

Table 2: Research situation and sample size

\begin{tabular}{cccc}
\hline City & $\begin{array}{c}\text { Permanent Resident Population } \\
\text { (million) }\end{array}$ & $\begin{array}{c}\text { Calculated Sample } \\
\text { Size }\end{array}$ & $\begin{array}{c}\text { Planned } \\
\text { Sample Size }\end{array}$ \\
\hline Chengdu & 15.918 & & \\
Chongqing & 30.484 & 384 & 1500 \\
Changsha & 7.645 & & \\
Hangzhou & 9.188 & & \\
Shanghai & 24.197 & & \\
\hline
\end{tabular}

184

185 After the sample size for each city is determined, it is necessary to consider location

186 distributions within each city in order to investigate the representative communities of each

187 city. Therefore, the locations of residential communities in each city were coded using a

188 random number generator to obtain the designated locations for survey. It

189 is worth noting that no standards such as postcode orders or location information were

190 applied during screening, which ensured the randomness of residential communities in

191 each city. As a result, 30 sampling sites were identified for each city, and the sample

192 distribution is shown in Figure 2. The red dots in Figure 2 are the survey sites, and the

193 colors of each region border correspond to the number of samples. All urban areas in the

194 five cities have ideal site representativeness, and, thanks to the random sampling, there is

195 no small probability deviation concentrating in a narrow range. 


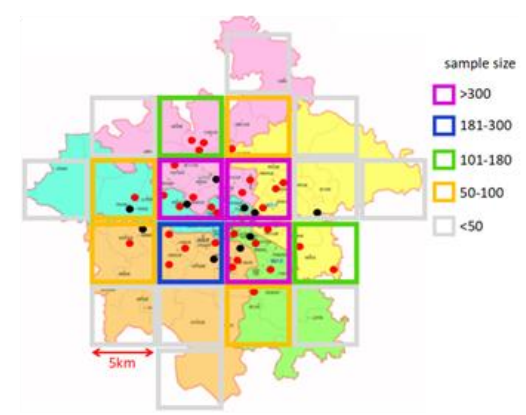

Chengdu

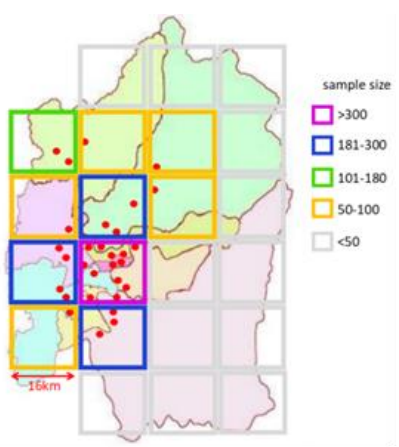

Chongqing

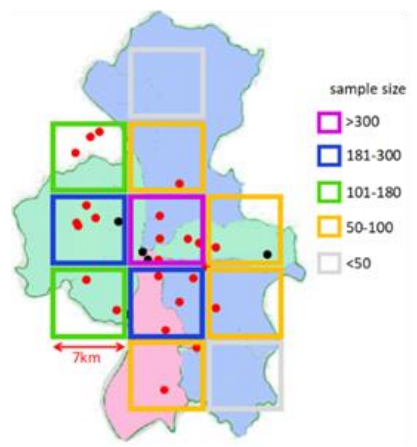

Changsha

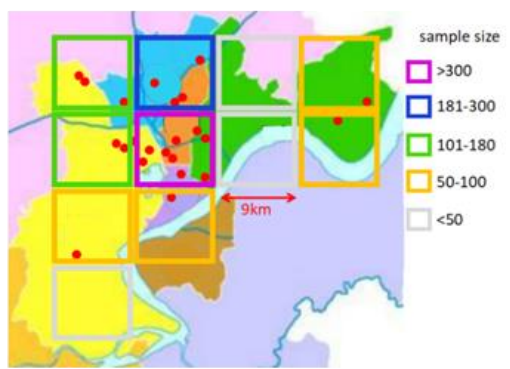

Hangzhou

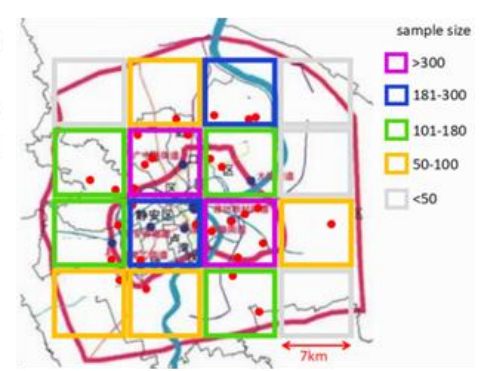

Shanghai

\subsection{Questionnaire Design}

199 A rigorous survey is based on research questions, theories, reasonable hypotheses, and

200 well-defined explanations of variables [42]. To meet the purpose of obtaining the data for

201 analysis and the research objectives of this study, the contents of the survey questionnaire

202 have been divided into two parts. The building construction information, family structure

203 of respondents, energy-matter behaviors and habits for winter heating and ventilation have

204 been partly optimized and recorded as the occupancy behavior schedules for the related

205 analysis of building heating energy consumption [43]. Explanations of how each part of

206 the questionnaire was designed to respond to the research questions are presented as

207 follows: 
208 Part 1 mainly includes the basic information on building characteristics such as building 209 construction age and dwelling size, family structure and time at home. According to the 210 year of the upgrading of building energy design codes, the construction age band is 211 classified as 'before 2001', '2001-2009', and 'after 2009'. Five family structures were 212 mainly considered referring to the statistical data from the 2016 China National Bureau of 213 Statistics [4]: (a) single (S); (b) couple (C); (c) couple with a child (CP+C); (d) couple with 214 child and the elderly (CCGP); (e) others - any family structure not listed.

215 Part 2 mainly focuses on how people heat their homes. Questions include "what are the 216 measures used for heating?", "how do people operate them?", and "what are the setting 217 points of the air conditioning?". Through desktop studies and heating appliance market 218 information, the research team listed commonly-used heating devices such as air 219 conditioning, under-floor heating, radiators, oil radiator heating, portable electric heater, 220 fan heater, electric blankets, hot-water bags, etc. and temperature setting-points, clothing 221 regulations, etc. To note, given that residents may have different behaviors in different 222 types of rooms, the occupant behaviors in the bedroom and living area were investigated 223 separately. These questions are expected to benefit researchers seeking to explore the real 224 heat demands in this region, as well as for policy makers for future heating applications 225 and building energy efficiency.

226 Many studies have confirmed that long-term occupants living in the HSCW zone have 227 habits of opening windows for fresh air, even in the winter time [44]. This could be one of 228 the most diverse and erratic behaviors due to individual differences and could significantly 229 affect thermal comfort and heating energy consumption [26]. Therefore, a question relating 230 to the window opening gap when heating is in use is included in the questionnaire.

231 The detailed framework of the questionnaire is shown in Figure 3. An appendix containing 232 the questionnaire is provided for reference. The questionnaire was presented in three 233 sections, in three sections of bedroom, living room and fresh air demands. Note that 234 background information, such as gender, age, occupation, family income range and so on 235 were designed in questionnaires but were exclusively considered in this study, considering 236 the main aims and propose of this study. 


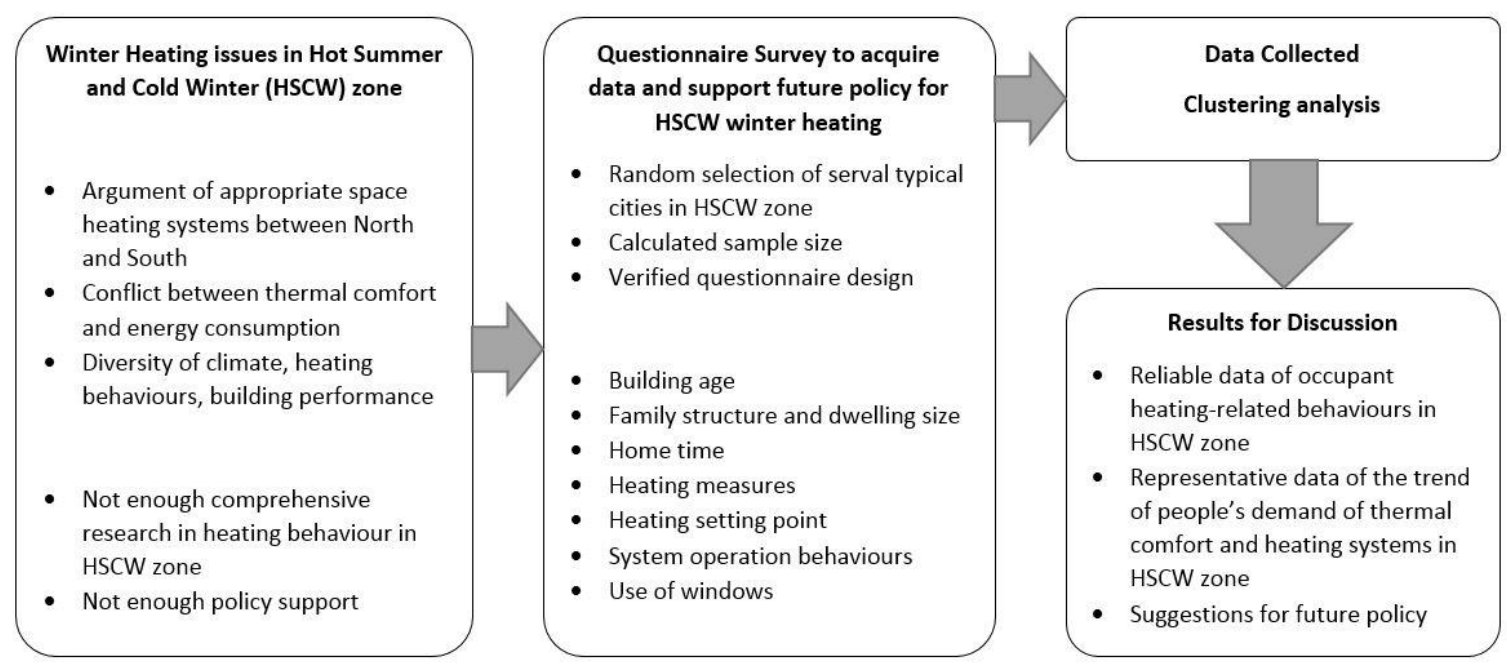

Figure 3: Framework of the questionnaire survey process

\subsection{Data screening and statistics}

240 1) Data collection

241 The surveys were conducted simultaneously in the selected sample locations of the five 242 cities from November 2017 to February 2018. The surveyors paid visits to the selected

243 communities in each city. A total number of 8,764 respondents completed the questionnaire

244 including samples of 1,619 from Chengdu; 2,196 from Chongqing; 1,197 from Changsha;

245 1,716 from Hangzhou; and 2,036 from Shanghai, by means of face-to-face completion of

246 paper-based forms or by using an electronic version as a social media we-chat app. After

247 screening null or invalid values, the sample size used in analysis was 8471.The survey in

248 each city met the required minimum sampling size which was indicated in Table 2,

249 ensuring the representative and valid analysis in the following results.

250 2) Validity and reliability analysis

251 We conducted a questionnaire reliability and validity testing in this study. Reliability 252 analysis and validity analysis are two methods to check the data quality in questionnaire, 253 where the former describes the degree of consistency of data from questionnaires in survey 254 during repeated measurements and the latter evaluates to what degree the results of the 
255 designed questions collected by questionnaires could reflect the real situations of occupants'

256 actual heating related behaviors.

257 For reliability analysis, the Alpha reliability coefficient method, i.e. Cronbach's Alpha, is 258 widely used to examine the inner consistency. The method is suitable for analyzing 259 designed question in questionnaires in this study. The calculation of the Alpha 260 coefficient is as follows [45]:

$$
\alpha=\frac{k}{k-1}\left(1-\sum_{i=1}^{k} \frac{s_{i}^{2}}{s_{p}^{2}}\right)
$$

262 Where,

263 k---- The number of items for the research objects;

$264 s_{i}^{2}$-.- The variance per item;

$265 s_{p}^{2}$-.-- The total variance of the observed items.

266 In addition, the validity analysis is mainly adopted to examine whether the designed 267 questions are able to reflect the real situations focused. The higher the values of validity 268 are, the more accurately the results obtained from questionnaires reflect the real features. 269 It is defined as the ratio $r_{x y}$ of variances of effective values and real values, as expressed in 270 Equation (3).

$$
r_{X Y}=\frac{S_{X}^{2}}{S_{Y}^{2}}
$$

272 The validity and reliability tests theoretically could be conducted before or after the survey;

273 the complemented survey would be re-conducted if the test was unacceptable. In this study, 274 the tests were conducted after the survey, and Table 3 shows the results of the validity and 275 reliability tests of different questions in the questionnaire. According to Refs. [45, 46], the 276 results are good when the reliability coefficient and validity coefficient are higher than 0.9; 277 and are acceptable when they are above 0.8. Conversely, when the values are lower than 278 0.7, the questionnaire should be re-designed and the research should be re-conducted in 
279 order to ensure scientific rigor. The results in Table 3 shows that for the target questions,

280 the coefficients $\alpha$ were all higher than 0.8 , indicating the question designs were good and

281 the questionnaires were acceptable. In addition, Table 3 shows that the values of validity

282 test were both higher than 0.7, suggesting the results obtained from the questionnaire

283 survey could efficiently reveal the heating behaviors of residents in this region. This lays

284 the foundation for the following analysis.

Table 3: Results of validity and reliability testing

\begin{tabular}{cllc}
\hline Method & \multicolumn{1}{c}{$\begin{array}{c}\text { Number of } \\
\text { questions(Appendix) }\end{array}$} & \multicolumn{1}{c}{ Contents description } & $\begin{array}{c}\text { Coefficients of Cronbach's } \\
\text { Alpha/KMO test }\end{array}$ \\
\hline $\begin{array}{c}\text { Reliability } \\
\text { Analysis }\end{array}$ & Q1,Q2,Q3 & Basic information and background & 0.80 \\
& Q8,Q10,Q11 & Heating-based behaviors in living room & 0.85 \\
& Q4,Q7 & Temperature set points in bedroom and living room & 0.91 \\
\hline $\begin{array}{l}\text { Validity } \\
\text { analysis }\end{array}$ & Q8,Q10,Q11 & Heating-based behaviors in living room & 0.74 \\
& Q4,Q7 & Temperature set points in bedroom and living room & 0.88 \\
& Q5,Q6,Q8,Q9,Q10,Q11 & $\begin{array}{l}\text { Occupants' behaviors during heating in bedroom } \\
\text { and living room }\end{array}$ & 0.79 \\
\hline
\end{tabular}

286 3) Statistical analysis

287 There are three types of variables from the questionnaire statistics: continuous variables

288 (e.g. AC setting points), dichotomous variables (e.g. ratio of HVAC behaviors), and ordinal

289 multiple variables (e.g. modes of HVAC behaviors), which correspond to different

290 conditions and analytical methods. Descriptive statistics were used first to give a profile of

291 occupant behaviors under different situations. The correlation analysis was used to evaluate

292 the relations among variables and the Kendall's tau-b correlation index was adopted to

293 describe the relations of two classified variables in questionnaires. The ANOVA test was

294 used to examine the differences in occupant behaviors during heating periods among the

295 five cities, and the post-analysis ANOVA was used to compare the differences among

296 different groups (e.g., family structures). The multi-way ANOVA was then conducted to

297 identify the factors that affect the temperature setting points of occupants according to four 
298 typical family structures. The cluster analysis was then employed to classify and

299 summarize the households according to the different heating-related behaviors of

300 occupants. All tests conducted were two-sided and any p-values less than 0.05 were 301 considered significant.

302

303 3. Results

304 The current study aimed to provide an overview of knowledge of heating related behaviors

305 of residents at homes in the Yangtze River region; the data from surveys from the five 306 cities were analyzed as a whole in the following analysis, regardless of the slight

307 differences among different cities.

$308 \quad 3.1$ Basic information from the survey

309 1) Building age

310 The census data on building construction age from the Real Estate source for each city has

311 been collected in Table 4 . In order to verify whether the building age proportions of this

312 study reflect the cities' real situations, data collected from this survey were compared to

313 the statistical data in Table 4. The most investigated buildings were built from 2001 to 2009

314 accounting for the highest proportion of $45 \%$. This was followed by buildings constructed

315 before 2001 with a proportion of $36.1 \%$. The proportion of buildings that were built after

3162009 was small, about 18.9\%. A close comparison shows that the distribution of

317 construction ages of investigated buildings exhibited a good consistency with the census

318 data, and no significant differences of construction ages were found between the statistics

319 and the surveyed results ( $t$ test, $p>0.05$ ). This ensures our survey truly reflects the real

320 building characteristics situation.

Table 4: Proportion of building age of this survey and the census data 


\begin{tabular}{cccc}
\hline & Before 2001 & $2001-2009$ & After 2009 \\
\hline Census data & $35.5 \%$ & $44.9 \%$ & $19.6 \%$ \\
Surveyed buildings & $36.1 \%$ & $45.0 \%$ & $18.9 \%$ \\
\hline
\end{tabular}

323 2) Family structure and dwelling size

324 The analysis of types of family structure and dwelling size can be seen in Table 5. Most

325 investigated families were couples, couples with children $(\mathrm{CP}+\mathrm{C})$, and couples with

326 children and the elderly (CCGP), accounting for 27\%, 33\% and 26\% respectively, which

327 reflects well the variety of family types. By analyzing the correlation coefficient $r$ between

328 the family structures and dwelling size, the correlation coefficients in Table 5 exhibit high

329 positive correlations $(\mathrm{p}<0.001)$. The bigger the family size is, the bigger the coefficient is,

330 indicating that the dwelling had more rooms. Single persons usually take one or two-

331 bedroom dwellings. Two-bedroom and three-bedroom dwellings are the popular types in

332 residential buildings and the most complex three-generation family structure are generally

333 found in three-bedroom dwellings. However, there were still a big proportion (0.49) of type

334 of family living in the two-bedroom dwellings.

Table 5: Correlation coefficient between family structures and dwelling types

Family structures Number of samples

\section{Dwelling type*}

One bedroom. Two bedrooms. Three bedrooms. Four bedrooms

\begin{tabular}{cccccc}
\hline Single & $1139(14 \%)$ & 0.3 & 0.40 & 0.27 & 0.03 \\
Couple & $2126(27 \%)$ & 0.14 & 0.56 & 0.26 & 0.04 \\
CP+C & $2597(33 \%)$ & 0.03 & 0.49 & 0.40 & 0.08 \\
CCGP & $2052(26 \%)$ & 0.02 & 0.32 & 0.56 & 0.10 \\
\hline
\end{tabular}

335 (Note: * the number of bedrooms in the investigated dwellings)

336 3) Times when residents are at home

337 The fact whether or not occupants are at home, significantly relates to the usage of

338 household heating. The percentage time spent at home as reported by respondents in each 
339 of the four family structures is shown in Figure 4. From the figure we can see that for the 340 family structure with children and the elderly (CCGP), $80 \%$ of respondents reported the 341 home time as daytime from 7:00 to 18:00; this proportion was around 50\% for couples and 342 couples with a child $(\mathrm{CP}+\mathrm{C})$. By contrast, single persons had the lowest home time during 343 daytime with around $20-30 \%$. These results reasonably reflect the activity characteristics 344 in residential buildings, which are believed to affect the heating modes and behaviors at 345 home. Wang et al. [8] found that retired couple/single households consume on average $34647 \%$ more energy than those with no retired members. This may be explained by a longer 347 heating duration needed by the households with retired members. Combined with Figure 3484 , families that include the elderly had a higher home time - 80\% - during daytime. This 349 may contribute to higher heating demands and energy consumption compared to other 350 family structures where occupants leave home for work during the daytime. Therefore, in 351 future, it would be worthwhile considering occupancy as a most important factor for 352 building energy efficiency design standards, energy efficiency policy-making, and 353 predicting energy consumption in the HSCW zone.
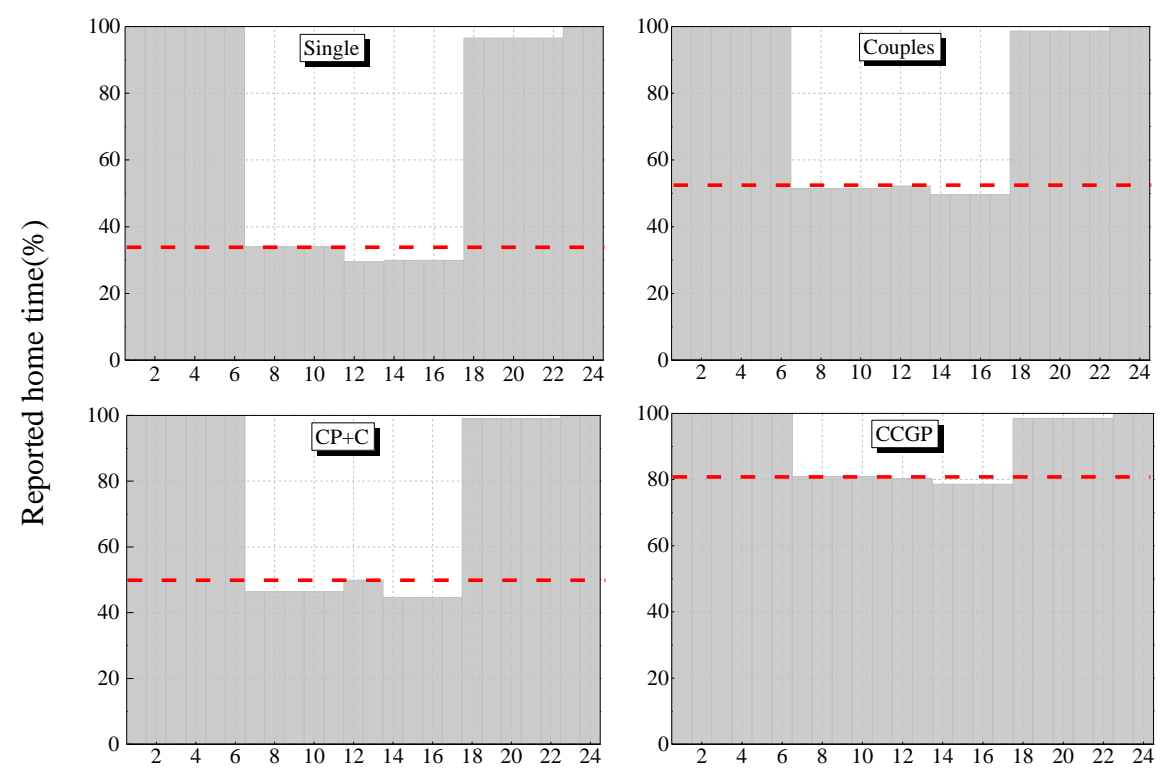

Time of day 
358 1) Heating measures

359 From this survey, $63 \%$ of respondents reported heating their bedroom and $43 \%$ their living 360 room, as shown in Figure 5. From the figure, we can see that the air conditioner (AC), or 361 air source heat pump (ASHP) were the most used for heating in winter. The proportions 362 using $\mathrm{AC}$ in bedrooms and living rooms were $63 \%$ and $58 \%$ respectively. This is in 363 agreement with Ref. [25] and with AC being the most commonly used heating device in 364 this region. In addition, Figure 5 further confirms that residents from the HSCW climate 365 zone do not heat their homes for 24-hours, unlike those in northern zones. There is still a 366 quite large proportion of residents that do not heat their home at all (37\% in the bedroom 367 and $57 \%$ in the living room, respectively), as seen in Figure 5.

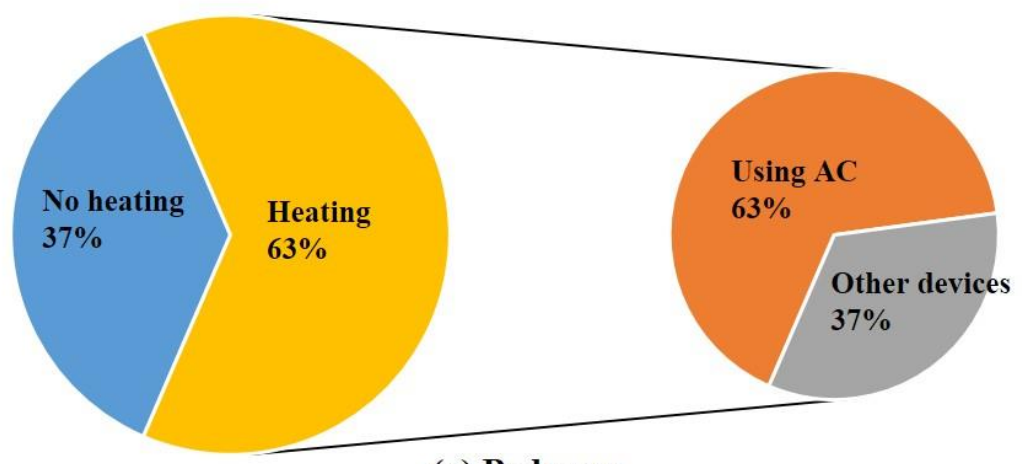

(a) Bedroom

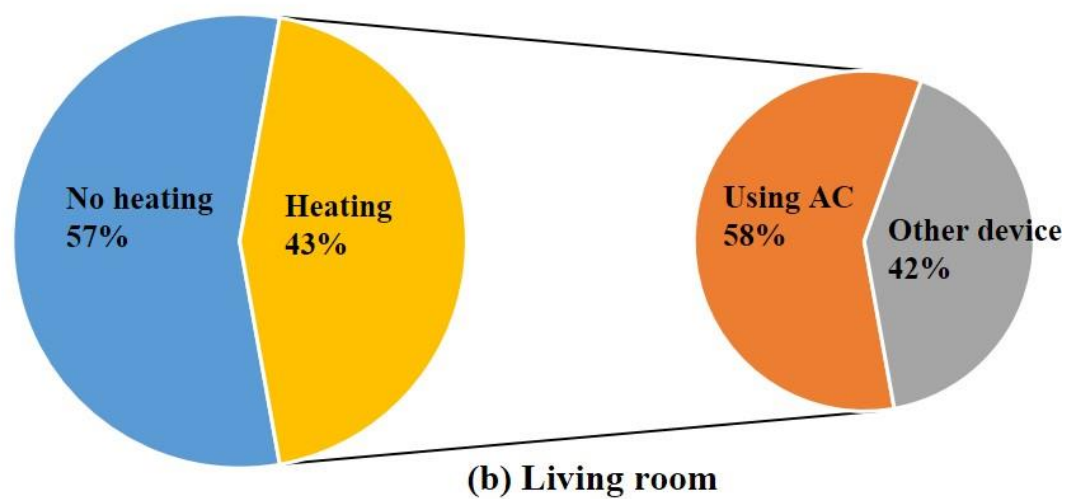

(b) Living room 
372 During the survey, a variety of heating measures were investigated. Apart from AC, Table

3736 lists the heating devices used by respondents and the corresponding proportions. A

374 variety of heating devices including under-floor heating, oil heaters, radiators, portable

375 electric heaters (infrared heaters, fan heaters, electric blankets) were found in households.

376 However, compared to the AC usage, all these devices accounted for a relatively lower

377 proportion ranging from 1\%-14\%. Therefore, it is reasonable to infer that, in the long run

378 and with technological development, AC will become the dominant form of heating.

Table 6: Heating devices applied in households in winter

\begin{tabular}{ccccc}
\hline \multirow{2}{*}{ Heating patterns } & \multicolumn{2}{c}{ Bedroom } & \multicolumn{2}{c}{ Living room } \\
& Cases & Proportion & Cases & Proportion \\
\hline Air conditioning (AC) & 4258 & $63 \% \%$ & 2424 & $58 \%$ \\
Underfloor heating & 207 & $3 \%$ & 154 & $4 \%$ \\
Oil heating radiant & 379 & $6 \%$ & 267 & $6 \%$ \\
Radiator & 188 & $3 \%$ & 150 & $4 \%$ \\
Infrared heater & 370 & $5 \%$ & 607 & $14 \%$ \\
Fan heater & 264 & $4 \%$ & 209 & $5 \%$ \\
Electric blanket & 860 & $13 \%$ & 43 & $1 \%$ \\
Other & 211 & $3 \%$ & 360 & $9 \%$ \\
\hline
\end{tabular}

380 2) Heating setting-point for AC

381 The temperature setting-points significantly affect the heating energy consumption. Figure

3826 shows the distribution of temperature settings during heating reported by respondents.

383 The sizes of the bubbles represent the sample capacity for reporting each temperature

384 setting point and they are marked in different colors to distinguish four typical family

385 structures. It can be seen that, regardless of family structures, the majority of occupants

386 chose to set the AC temperature within the range $24-28^{\circ} \mathrm{C}$, with higher proportions and

387 bigger bubble sizes. 


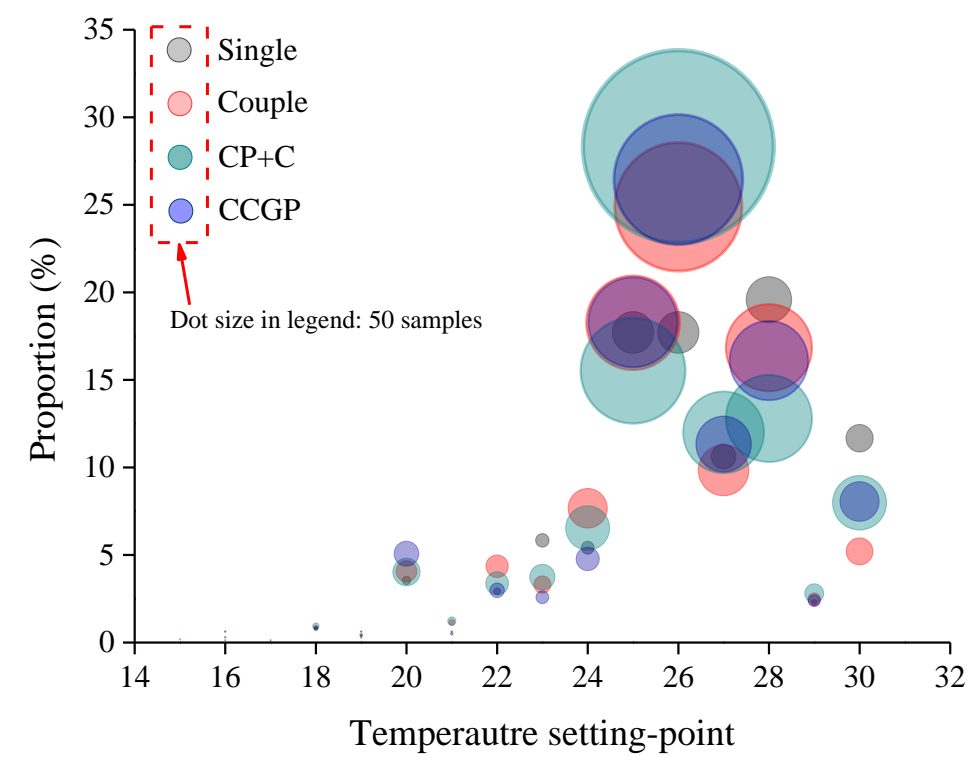

Figure 6: Temperature setting point distribution with different family structures

391 Figure 7 shows the distribution of temperature setting-points by different family structures.

392 We can clearly see that the mean temperature setting-points in both bedrooms and living 393 rooms are overwhelmingly high, in the range $25-28^{\circ} \mathrm{C}$. Though the mean temperature

394 setting points for each of the four family structures are close, the statistical results shows 395 that the factor of family structure has significant effect on the temperature setting-points 396 (ANOVA, $\mathrm{p}<0.05$ ). Similar trends were found for living rooms. This setting-point 397 temperatures are much higher than those in northern China [39]. Compared to a study from 398 the UK [47], this figure seems unacceptably high. This phenomenon can be explained as 399 being based on the 'part-time-part-space' heating style, the room temperature for an 400 unheated room is usually very low (e.g. low indoor temperatures of around $12^{\circ} \mathrm{C}$ for 401 unheated space in the HSCW area [25]). However, occupants expect a speedy temperature 402 increase when they enter into unheated rooms, which brings us to the next question about 403 how people operate the heating devices. 


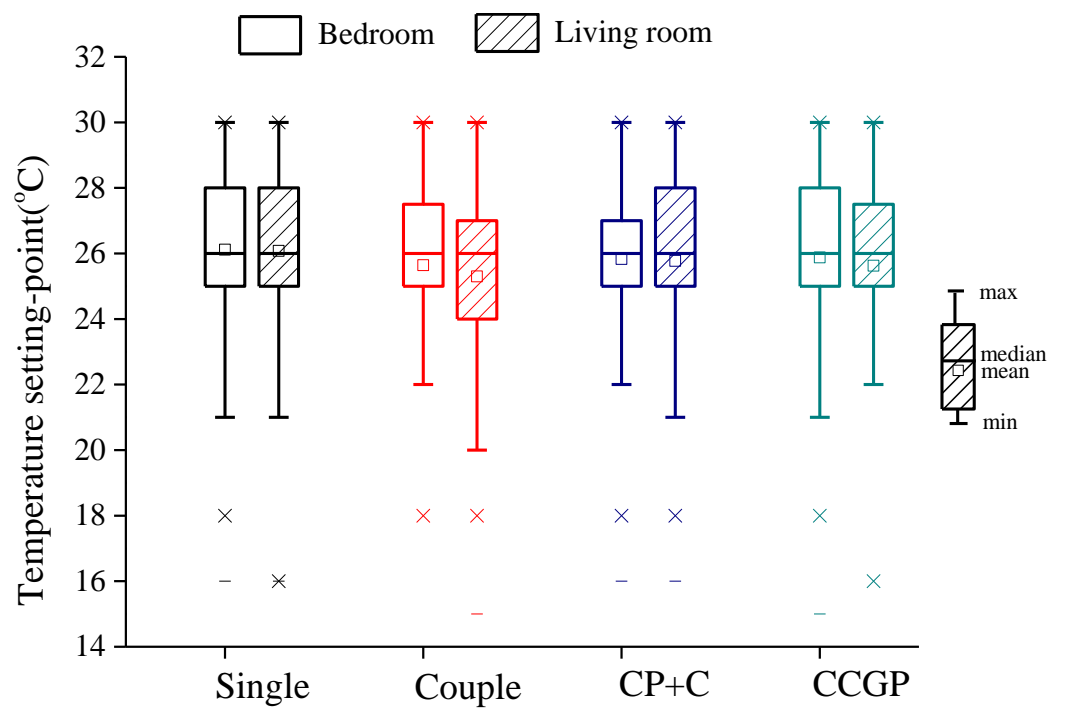

405 Figure 7: Temperature setting-points in different room types with different family structures

407 3) AC operation behaviors

408 In order to further understand how the urban residents operate AC for heating, Q6 and Q11 409 specifically ask this question for bedrooms and living rooms. From the survey, 1,989 410 respondents reported their AC operation modes as seen in Table 7. For bedroom, three 411 similar modes were almost equally used when occupants slept. That is, nearly $34 \%$ of 412 respondents chose to set a constant temperature all night; $37 \%$ of respondents set a timing 413 mode whilst $29 \%$ of respondents used the sleep mode integrated into the AC, indicating 414 occupants' different individual preferences for using AC modes.

Table 7: Operation modes when AC on

\begin{tabular}{clc}
\hline $\begin{array}{c}\text { Room } \\
\text { types }\end{array}$ & \multicolumn{1}{c}{ Q6-AC using modes } & Cases/proportion \\
\hline $\begin{array}{c}\text { Living } \\
\text { room }\end{array}$ & Set a constant temperature & $1989 / 80 \%$ \\
& $\begin{array}{l}\text { Set a high temperature at start and turn down when the room get } \\
\text { warm }\end{array}$ & $490 / 20 \%$ \\
\hline Bedroom & Set a constant temperature all night & $1010 / 34 \%$ \\
& Set a timing mode & $1086 / 37 \%$
\end{tabular}


416 Note: The sleep mode is an operation algorithm embedded in the AC by manufacturers. The maximum

417 operation time is 8 hours in order to save energy

418 We further explored the temperature setting-points responding to each mode of use and a 419 statistical test was conducted to examine whether the AC modes used by occupants affect 420 the temperature setting points. We counted the distribution of temperature setting-points 421 under each mode of using AC; the results are shown in Table 8. From the table, we can see 422 that for living rooms, when respondents reported they set a high temperature first and then 423 turned it down when the room became warmer, the majority set a temperature higher than $42426^{\circ} \mathrm{C}(65 \%)$. This was similarly remarkable when respondents reported setting a constant 425 temperature in living rooms. The ANOVA test shows a significant difference in living 426 rooms (ANOVA, $\mathrm{p}<0.05$ ), suggesting that the setting temperature in the living room was 427 significantly affected by occupants' modes of using AC. This was consistent with Table 7 428 which suggests that most occupants set constant temperatures when AC was on.

429 For bedrooms, the trends of temperature setting points under each mode of use were similar 430 to those for living rooms. Regardless of the mode of using AC, a large number of occupants 431 chose to set a temperature of over $26^{\circ} \mathrm{C}$, and the proportion was higher than $60 \%$, even up 432 to $67 \%$ when the mode of use was to set a constant temperature all night. $60 \%$ of 433 respondents chose to set a temperature setting-point over $26^{\circ} \mathrm{C}$. Such results explain why 434 the setting points in Figures 6 and 7 were so high. 
Table 8: AC mode of use and the corresponding temperature setting points

\begin{tabular}{|c|c|c|c|c|}
\hline Room types & $\mathrm{AC}$ using modes & $\begin{array}{l}\text { Temperature } \\
\text { settings }\left({ }^{\circ} \mathrm{C}\right)\end{array}$ & Cases & Proportion (\%) \\
\hline \multirow[t]{8}{*}{ Living room. } & \multirow{4}{*}{$\begin{array}{c}\text { Set a high temperature } \\
\text { at start and turn down } \\
\text { when the room gets } \\
\text { warm. }\end{array}$} & $<18$ & 1 & $0 \%$ \\
\hline & & $18 \leq$ Tset $<24$ & 83 & $20 \%$ \\
\hline & & $24 \leq$ Tset $<26$ & 60 & $15 \%$ \\
\hline & & $\geq 26$ & 272 & $65 \%$ \\
\hline & \multirow{4}{*}{$\begin{array}{l}\text { Set a constant } \\
\text { temperature. }\end{array}$} & $<18$ & 16 & $1 \%$ \\
\hline & & $18 \leq$ Tset $<24$ & 296 & $17 \%$ \\
\hline & & $24 \leq$ Tset $<26$ & 378 & $22 \%$ \\
\hline & & $\geq 26$ & 1053 & $60 \%$ \\
\hline \multirow[t]{12}{*}{ Bedroom. } & \multirow{4}{*}{$\begin{array}{c}\text { Set a constant } \\
\text { temperature all night. }\end{array}$} & $<18$ & 3 & $0 \%$ \\
\hline & & $18 \leq$ Tset $<24$ & 91 & $10 \%$ \\
\hline & & $24 \leq$ Tset $<26$ & 216 & $23 \%$ \\
\hline & & $\geq 26$ & 642 & $67 \%$ \\
\hline & \multirow[t]{4}{*}{ Set a timing mode. } & $<18$ & 7 & $1 \%$ \\
\hline & & $18 \leq$ Tset $<24$ & 135 & $14 \%$ \\
\hline & & $24 \leq$ Tset $<26$ & 225 & $23 \%$ \\
\hline & & $\geq 26$ & 605 & $62 \%$ \\
\hline & \multirow{4}{*}{$\begin{array}{l}\text { Use the sleep mode } \\
\text { embedded in the AC. }\end{array}$} & $<18$ & 2 & $0 \%$ \\
\hline & & $18 \leq$ Tset $<24$ & 100 & $13 \%$ \\
\hline & & $24 \leq$ Tset $<26$ & 181 & $24 \%$ \\
\hline & & $\geq 26$ & 475 & $63 \%$ \\
\hline
\end{tabular}

437 Many scholars have conducted research on occupant window-opening behavior and found 438 that people living in the HSCW climate zone have a habit of opening windows, even in 439 winter [10, 31, 44]. The main driving force of this habit is inferred to be a high demand for 440 fresh air. In this study, Q5 and Q9 explore whether people open windows when they use 
441 heating. The results are shown in Table 9. We can clearly see that although the AC was 442 used for heating, around half of occupants chose to open windows with a small gap, $49 \%$ 443 for the bedroom and $57 \%$ for the living room respectively.

Table 9: Window open/close in bedroom and living room when using AC

\begin{tabular}{lcc}
\hline Window operating modes & Bedroom & Living room \\
\hline Closed totally. & $49 \%$ & $40 \%$ \\
Open with a small gap. & $49 \%$ & $57 \%$ \\
Open with a big gap. & $2 \%$ & $3 \%$ \\
\hline
\end{tabular}

444 From Figures 6-7 and Table 8, occupants preferred to set high temperatures when using 445 AC for heating; while Table 9 reveals that occupants tended to open windows during 446 heating use. Therefore, such occupant behavior is believed to relate to the heating 447 efficiency in rooms, which may affect the occupants' temperature setting points for AC. 448 As a result, we analyzed the relationship between the temperature setting-points (Q4/Q7) 449 and the operation of windows by occupants (Q5/Q9), as shown in Table 10.

450 It can be seen that, whether for bedroom or living room, when the setting temperature 451 increases, both the proportions for windows open and closed increased. In particular, when $452 \mathrm{AC}$ was set higher than $26^{\circ} \mathrm{C}$, the proportion of windows being closed was the highest, 453 accounting for $65 \%$ and $62 \%$. However, there were still high proportions of occupants who 454 chose to open windows with a small gap, 59\% and 61\% respectively. By contrast, 59\% of 455 respondents reported a big gap for window opening in bedrooms, and $36 \%$ in the living 456 room. The statistical results show that the temperature setting-points were significantly 457 affected by the window operations in bedrooms (ANOVA, p<0.05); while no significant 458 difference was found between temperature setting-points and window operations in living 459 rooms (ANOVA, $\mathrm{p}>0.05$ ). This further verified that occupants in this region have a 460 significant habit of leaving windows open with a gap - small or large - for fresh air when 461 heating was applied.

Table 10: Relationships between temperature settings of AC and window open/closed 


\begin{tabular}{ccccc}
\hline Room types & $\begin{array}{c}\text { Temperature } \\
\text { settings }\end{array}$ & Close totally & Open with a small gap & Open with a large gap \\
\hline \multirow{3}{*}{ Bedroom } & $<18$ & $1 \%$ & $1 \%$ & $0 \%$ \\
& $24 \leq$ Tset $<24$ & $11 \%$ & $16 \%$ & $12 \%$ \\
& $\geq 26$ & $23 \%$ & $24 \%$ & $29 \%$ \\
& Total cases & 2079 & $59 \%$ & $59 \%$ \\
& $<18$ & $1 \%$ & 1889 & 51 \\
\hline \multirow{2}{*}{ Living room } & $18 \leq$ Tset $<24$ & $16 \%$ & $1 \%$ & 0 \\
& $24 \leq$ Tset $<26$ & $21 \%$ & $19 \%$ & $52 \%$ \\
& $\geq 26$ & $62 \%$ & $19 \%$ & $36 \%$ \\
& Total cases & 1055 & $61 \%$ & 25 \\
\hline
\end{tabular}

\subsection{Cluster analysis of occupants' heating-related behaviors}

464 In this study, we have confirmed that there are a variety of behaviors relating to winter 465 heating which makes identifying household characteristics in terms of winter heating 466 behavior complex. In order to generalize the characteristics of heating-related behaviors in 467 different households, the cluster analysis method has been applied. This is a method widely 468 employed in field studies to subdivide a set of observations into subsets, where the same 469 clusters are highly similar, meantime, different clusters have low similarity [48]. The two470 step clustering analysis takes advantage of using both discrete and continuous variables as 471 inputs and of building clusters with the optimal variables and proportions, hence its use in 472 this analysis.

473 At the first stage, the 'exhaustive search' method is used to select the feature factors that 474 enable the characteristics of occupant behavior related to heating to be represented. Then, 475 during clustering analysis, keeping a 'goodness of fit' and retaining input factors and 476 behaviors were two principles adopted to debug the model. Building a debug model which

477 aims at keeping to these principles forms the second stage. We adopted the logarithmic 
478 likelihood method to evaluate the distances between different clusters and the number of 479 clusters referring to the Schwarz Bayes Criterion (BIC Bayesian information criterion). 480 Therefore, the different clusters with different factors were calculated. Accordingly, seven 481 heating-related factors were screened in three clusters, which enabled the features in 482 different clusters to be characterized.

483 Table 11 shows the results of cluster analysis. From Table 11, Cluster 1 was likely to be 484 the working mode, as in this group occupants only or mainly used AC in the evening. This 485 group was matched to behavior modes with shorter 'AC on' times (only evening). In 486 addition, occupants in this group tended to keep windows closed in the living room and 487 bedroom when using AC. This indicated that occupants in Cluster 1 have frugal heating488 use behaviors. By contrast, Cluster 2 and Cluster 3 show a behavior pattern of being at 489 home all day and having higher proportions of periods when windows are open when using 490 AC, which is different from Cluster 1. The difference between Cluster 2 and Cluster 3 is 491 that people in Cluster 3 depended heavily on AC, and use AC as long as they are in the 492 living room. Besides, occupants in Cluster 3 keep the AC on in bedroom throughout the 493 night until next day, indicating a more luxurious behavior when using AC for household 494 heating. Overall, the cluster analysis in Table 11 identifies seven significant factors 495 affecting heating in rooms and generalizes the behaviors in different groups, which gives 496 us a holistic insight into occupants' heating-related behaviors and a general profile of 497 clustering occupants' behavior characteristics. 
Table 11: Results of cluster analysis when using AC for heating

\begin{tabular}{|c|c|c|c|c|}
\hline \multirow{2}{*}{$\begin{array}{c}\text { No } \\
*\end{array}$} & \multirow{2}{*}{$\begin{array}{l}\text { Variables } \\
\text { included in model }\end{array}$} & \multicolumn{3}{|c|}{ Levels /proportion** } \\
\hline & & Cluster 1 & Cluster 2 & Cluster 3 \\
\hline 1 & $\begin{array}{l}\text { AC use in living } \\
\text { room }\end{array}$ & $\begin{array}{c}\text { Only use } \\
\text { when feeling cold } / 100 \%\end{array}$ & $\begin{array}{l}\text { Only use } \\
\text { when feeling } \\
\text { cold } / 100 \%\end{array}$ & $\begin{array}{l}\text { Use as long as } \\
\text { room occupied/100\% }\end{array}$ \\
\hline 2 & $\begin{array}{l}\text { Heating } \\
\text { with/without } \\
\text { window opening in } \\
\text { bedroom**** }\end{array}$ & $\begin{array}{l}\text { AC without window } \\
\text { opening } / 100 \%\end{array}$ & $\begin{array}{l}\text { AC with window } \\
\text { opening } / 100 \%\end{array}$ & $\begin{array}{l}\text { AC with window } \\
\text { opening } / 51.5 \%\end{array}$ \\
\hline 3 & $\begin{array}{l}\text { Heating } \\
\text { with/without } \\
\text { window opening in } \\
\text { living room**** }\end{array}$ & $\begin{array}{l}\text { AC without window } \\
\text { opening gap } / 74.6 \%\end{array}$ & $\begin{array}{l}\text { AC with window } \\
\text { opening gap } / 81.3 \%\end{array}$ & $\begin{array}{c}\text { AC with window opening } \\
\text { gap } / 58.8 \%\end{array}$ \\
\hline 4 & $\begin{array}{l}\text { Use modes of AC } \\
\text { before sleep }\end{array}$ & $\begin{array}{l}\text { Keep on till next } \\
\text { day } / 38.1 \%\end{array}$ & Set time off $/ 42.4 \%$ & $\begin{array}{l}\text { Keep on until next } \\
\text { day } / 45.4 \%\end{array}$ \\
\hline & $\begin{array}{l}\text { AC temperature set } \\
\text { points in bedroom } \\
/{ }^{\circ} \mathrm{C}^{* * *}\end{array}$ & 26 & 26 & 26 \\
\hline 6 & Presence at home & Evening only/41.4\% & All day $/ 42.8 \%$ & All day $/ 43.3 \%$ \\
\hline 7 & $\begin{array}{l}\text { AC temperature set } \\
\text { points in living } \\
\text { room } /{ }^{\circ} \mathrm{C}^{* * *}\end{array}$ & 26 & 26 & 25 \\
\hline Ove & erall proportion/cases & $46 \% / 575$ & $39 \% / 493$ & $15 \% / 194$ \\
\hline \multicolumn{5}{|c|}{$\begin{array}{l}*: \text { the order indicates the importance of factors varying from high to low during modeling; } \\
* * \text { : the proportion means how many cases that are in agreement with the feature of such behavior in } \\
\text { this cluster; } \\
\text { ***: it is the average value of the investigated cases, instead of the proportion; } \\
* * * * \text { : there are three choices responding to occupant window-opening behaviors. However, for } \\
\text { clustering, the two choices where respondents reported opening a window with a small gap and with a } \\
\text { big gap were combined as a window opening gap. }\end{array}$} \\
\hline
\end{tabular}

\section{4.1 Appropriate heating modes and policies in the HSCW zone}

508 As discussed in the introduction and literature review, the appropriate space heating

509 approach for the HSCW climate zone has been widely argued for a long time. From the

510 statistics and standards, the settings between these two heating modes could be very 
511 unbalanced. In Northern China in the Severe Cold and Cold zones, the central heating 512 system provides continuous space heating hot water from stations to radiators for every 513 room, with a very luxurious $24 / 7$ mode during the entire heating period, and the set point 514 temperature is at least $18^{\circ} \mathrm{C}$. However, in the $\mathrm{HSCW}$ zone, as seen in this survey study, AC 515 is used as the means for winter space heating and is usually available in bedrooms and 516 living rooms, with a part-time mode when the room is occupied, for a shorter cold weather 517 period. Furthermore, although the setting-point temperature for AC could be higher than $51826^{\circ} \mathrm{C}$, it is discussed that studies [24] have still shown the average indoor temperature in 519 reality is only around $15^{\circ} \mathrm{C}$ for the heated rooms due to the complex factors of equipment 520 efficiency, poor thermal insulation, infiltration, and window-opening habits. Therefore, the 521 potential energy demand in future for better thermal comfort is enormous to achieve the 522 comfort level in the range $18^{\circ} \mathrm{C}$ to $28^{\circ} \mathrm{C}[3,49]$.

523 Comparatively, statistics and data showed that the average heating energy consumption for 524 urban heating in northern China was $15.1 \mathrm{kgce} / \mathrm{m}^{2}$ in 2016 [39]. For the HSCW zone, 525 current heating energy intensity is proven to be $3.6 \mathrm{kWh} / \mathrm{m}^{2}$ [24]. However, it is predicable 526 that the average indoor temperature in $\mathrm{HSCW}$ winter will be improved to a better condition 527 at $18^{\circ} \mathrm{C}$, and it is questionable about what would happen to the overall heating energy 528 consumption in the HSCW zone if the entire heating system was to be rebuilt as a central 529 heating system.

530 This unstoppable demand for indoor thermal comfort improvement could be an extremely 531 ambitious challenge for national policies on energy conservation [47]. Although the current 532 heating energy use intensity is low as $3.6 \mathrm{kWh} / \mathrm{m}^{2}$, the current heating method in the HSCW 533 zone - the 'part-time and part space' method - could provide a smoother path towards 534 increasing the energy load given people's requirements for improved thermal comfort [48]. 535 Accordingly, focusing on increasing insulation performance and the energy efficiency of 536 equipment based on this method is a widely-proven $[50,51]$ and better approach to 537 reducing energy waste and carbon emissions rather than changing the whole heating system 538 in this region. Jiang et al. [52] once discussed and studied that to achieve the energy 539 conservation and environmental protection objectives set by the national government, the 
540 energy benchmark for summer cooling and winter heating in the HSCW zone should be

541 limited within $20 \mathrm{kWh} / \mathrm{m}^{2}$. As the HSCW zone also has enormous energy demand for

542 summer cooling [9], there is not too much left for the space heating energy increase. If

543 completely copying the northern central heating system to the HSCW zone, the sudden

544 increase in energy consumption could be extremely massive; which is unacceptable. As a

545 result, this study believes that the very 'luxurious' central heating system should not be

546 applied to the HSCW zone, instead, improving the current separate heating system is a

547 smarter choice that fits into China's national development policy. Building design and

548 refurbishment as well as operation management is recommended to refer to the spatial and

549 temporal elements of the end-users' heating demand.

$550 \quad 4.2$ Outlook of future studies

551 The current study mainly focused on the behaviors and measures taken by occupants at 552 homes to improve and adapt to the indoor thermal environments in winter, providing a 553 general profile of heating situations in residential buildings in this region. The diverse 554 demographic factors (eg., age, numbers), building characteristics (e.g., construction ages, 555 insulation, air infiltration), socio-economic factors (e.g. family incomes), are exclusively 556 considered in our analysis. In fact, they are various driving factors underlying the 557 occurrence of a certain heating behavior of occupants. For example, the family structure 558 plays dominant role affecting the heating behaviors that as a whole, the behaviors of one 559 resident would be affected by family members. Family incomes was also a key determining 560 the use patterns and intensity of heating [48]. Moreover, since the heating patterns and 561 devices vary in homes, the factors and motivations changed over time, thus influencing the 562 heating behaviors and future energy use intentions in this region [31]. Given that the large563 scale survey mainly focuses on observation of the phenomena, we have conducted more 564 in-depth focus group interviews and surveys in small samples, aiming to exploring the 565 motivations, preferences, ect., and explaining the reasons behind theses heating related 566 behaviors. In addition, considering that occupant heating-related regulations may be 567 affected by the temporal-special usage patterns, demographic factors as well as their 568 impacts on energy consumption, the use behaviors for AC by residents, including 
569 temperature setting, modes, durations, indoor and outdoor temperatures have been

570 monitoring in several demonstration households of this region; the data results, however,

571 are our undergoing research works, which would be presented in future.

572 Research on holistic solutions for winter heating specifically suitable for this region should

573 not only consider performance improvements in the building passive technologies and

574 energy devices and systems, but also consider the operation strategies (people's usage

575 behaviors) and real comfort demands, in order to efficiently use energy for winter heating.

576 Heating energy modeling is important for the energy prediction at the domestic stock level.

577 The findings of this study of occupant behavior patterns for different clustered groups have

578 been incorporated into the modeling in our present research work and provided more 579 realistic boundary settings in models, to optimize the solutions for passive technologies for

580 new buildings and existing buildings and balance the multiple objectives of thermal

581 comfort and energy consumption quota. This is believed to allow predictions of different

582 energy demands and the possible energy-saving potential during heating periods in this 583 region.

584 The current study pays attentions to residents' related features affecting heating in winter.

585 Notably, the building envelope characteristics indeed play dominant roles on heating 586 choices and energy outcomes. For example, the thermal performance and air tightness of 587 existing buildings are poor in this region, and the insulation levels in terms of U-value that 588 suits the region are expected to be clear. The solutions to solve the air infiltration arising 589 from the habit of leaving windows open to allow a gap for fresh air should be a research 590 focus. Sensor technologies can be applied to provide occupants with information on 591 internal air temperature, humidity, and $\mathrm{CO}_{2}$ concentration which will help achieve 592 appropriate operation. Fresh air supply devices should be compulsory when air-tightness 593 is implemented. Energy policy codes for energy-efficient design specifically for this region 594 should be updated based on in-depth studies.

\section{5. Conclusions}


596 This study developed a holist method to conduct a large-scale field survey on winter

597 heating in domestic homes in the hot summer and cold winter climate zone in the Yangtze

598 River region. The method is rigorous in terms of determination of location, community 599 area, sampling size, and questionnaire design. A set of valid 8,471 sets of questionnaires

600 were collected from the five capital/municipality cities namely, Chengdu, Chongqing, 601 Changsha, Hangzhou, and Shanghai, covering the upper, middle and downstream regions 602 of the Yangtze River. The distribution of the sample size of building construction ages is 603 consistent with that of the China National Bureau of Statistics, which confirms the 604 representativeness of this survey. The main outcomes from the survey can be summarized 605 as follows:

606 (1) There is a high correlation between the size of the family structure and the size of 607 dwelling; the more family members, the bigger the dwelling;

608 (2) The winter heating for homes does not reach full capacity. Only 63\% reported heating 609

610 (3) Air conditioners (called AC) is the major device that is popularly used for winter 611 heating in the hot summer and cold winter climate zone, indeed AC accounts for 63\% 612 of bedroom and $58 \%$ of living room heating. The remaining uses include a large variety 613 of devices e.g. under-floor heating, oil heaters, radiators, electric heaters, etc., but the 614 proportions are relatively low, about 1\% (electric blanket) to14\% (infrared heater).

615 (4) Urban residents in this region heat their home in ways that are highly dependent on 616 their occupancy of space. This means the heating usage is intermittent as a kind of 617 'part-time-part-space', which is completely different to the heating mode involving a 618 central heating system with continuing operation in northern China.

619 (5) The temperature setting-point of $\mathrm{AC}$ is around $26^{\circ} \mathrm{C}$, with statistically significant 620 differences among different family structures. This does not mean the room 621 temperatures reach $26^{\circ} \mathrm{C}$. The high temperature setting is mainly due to the AC usage 
patterns: $80 \%$ of occupants set a constant temperature in the living room but tended to set a timing mode $(37 \%)$ or use the sleep mode $(29 \%)$ in the bedroom.

624 (6) People living in this region have a strong demand for fresh air, with nearly half of occupants opening the windows to provide a gap in winter when using heating. The

(7) The two-step clustering analysis classifies three clusters of heating-related behaviors proportions of window close/open increase with increasing temperature setting points when the AC is operating, indicating a coupled interaction of heating-related behaviors by occupants. using seven significant factors: occupants in Cluster 1 only or mainly used AC in the evening, matching to a shorter time when the AC is on and keeping windows closed when using AC, which indicated a frugal heating use behavior. Cluster 2 and Cluster 3 have higher proportions of window opening when using AC and people in Cluster 3 depended heavily on $\mathrm{AC}$, using it as long as they are in the living room and keeping the AC on during the whole night, which indicates a more luxurious behavior for AC household heating.

The research is supported by the China National Key R\&D Programme 'Solutions to Heating and Cooling of Buildings in the Yangtze River Region' SSHCool project [Grant No. 2016YFC0700300/1] and the China Fundamental Research Funds for the Central Universities [Grant No. 2018CDJDCH0015]. The research work is also related to the UKChina collaborative research project 'Low carbon climate-responsive Heating and Cooling of Cities (LoHCool)' supported by the National Natural Science Foundation of China [NSFC Grant No. 51561135002] and the UK Engineering and Physical Sciences Research Council [EPSRC Grant No. EP/N009797/1]. The authors would like to thank people, including Ruofei Liang, Bo Li, Xin Zhang, Yue Zhang, Fanbin Zeng, Yiwen Yan, Yan Li, Shangyan Wu, Yifan Li, Yuyi Fu, Fei Ren fromChongqing University, Xinzhen Wang from Zhejiang University, Yang He, Huixin Hu, Yuan Song from Tongji University, Min 


\section{References}

653 [1] Chinese Plan Publication House, "GB 50178, Standard of Climate Regionalization for 654 Architecture," ed. Beijing, 1993.

655 [2] B. Li, R. Yao, Q. Wang, and Y. Pan, "An introduction to the Chinese Evaluation Standard for the indoor thermal environment," Energy and Buildings, vol. 82, pp. 27-36, 2014.

657 [3]B. Li, C. Du, R. Yao, W. Yu, and V. Costanzo, "Indoor thermal environments in Chinese 658 residential buildings responding to the diversity of climates," Applied Thermal Engineering, vol. 659 129, pp. 693-708, 2018.

660 [4] National Bureau of Statistics of China. (2016). China population statistics. Available: 661 http://data.stats.gov.cn

662 [5]C. Peng, D. Yan, S. Guo, S. Hu, and Y. Jiang, "Building energy use in China: ceiling and 663 scenario," Energy and Buildings, vol. 102, pp. 307-316, 2015.

664 [6]H. Xiao, Q. Wei, and Y. Jiang, "The reality and statistical distribution of energy consumption 665 in office buildings in China," Energy and Buildings, vol. 50, pp. 259-265, 2012.

666 [7]S. Hu, D. Yan, Y. Cui, and S. Guo, "Urban residential heating in hot summer and cold winter 667 zones of China-Status, modeling, and scenarios to 2030," Energy Policy, vol. 92, pp. 158-170, 6682016.

669 [8]Z. Wang, Z. Zhao, B. Lin, Y. Zhu, and Q. Ouyang, "Residential heating energy consumption 670 modeling through a bottom-up approach for China's Hot Summer-Cold Winter climatic region," 671 Energy and Buildings, vol. 109, pp. 65-74, 2015.

672 [9] Ministry of Housing and Urban-Rural Development of the People's Republic of China, "JGJ 673 134-2010, Design standard for energy efficiency of residential buildings in hot summer and cold 674 winter zone," ed. Beijing: MOHURD, 2010.

675 [10] B. Lin, Z. Wang, Y. Liu, Y. Zhu, and Q. Ouyang, "Investigation of winter indoor thermal 676 environment and heating demand of urban residential buildings in China's hot summer - Cold 677 winter climate region," Building and Environment, vol. 101, pp. 9-18, 2016.

678 [11] Z. Wang, J. Zhang, and D. Zhang, "Global zoning for landscape plant introduction with the 679 method of fuzzy analogy preferred ratio to Shanghai, Chin," Landsc. Archit, vol. 28, no. 1, 2012.

680 [12] L. Xu, J. Liu, J. Pei, and X. Han, "Building energy saving potential in Hot Summer and Cold 681 Winter (HSCW) Zone, China-Influence of building energy efficiency standards and 682 implications," Energy Policy, vol. 57, pp. 253-262, 2013. 
683 [13] C. Su, H. Madani, and B. Palm, "Heating solutions for residential buildings in China: Current 684 status and future outlook," Energy Conversion and Management, vol. 177, pp. 493-510, 2018.

685 [14] FinancePeople.com. (2014). District heating in southern China is unappropriate. Available: 686 http://finance.people.com.cn/GB/8215/356561/373167/

687 [15] Xinhua News Agency. (2015). Xinhua News Agency: "Southern heating" has become a 688 consensus, and there are still differences in concentration or dispersion. Available: 689 https://www.thepaper.cn/newsDetail_forward_1397388

690 [16] T. Huo et al., "China's energy consumption in the building sector: A Statistical Yearbook691 Energy Balance Sheet based splitting method," Journal of Cleaner Production, vol. 185, pp. 665$692679,2018$.

693 [17] S. Hu, D. Yan, J. An, S. Guo, and M. Qian, "Investigation and analysis of Chinese residential 694 building occupancy with large-scale questionnaire surveys," Energy and Buildings, vol. 193, pp. 695 289-304, 2019.

696 [18] Tsinghua University Building Energy Research Center, 2013 Annual Report on China 697 Building Energy Efficiency. Beijing: China Architecture \& Building Press, 2013.

698 [19] D. Yan et al., "Occupant behavior modeling for building performance simulation: Current state 699 and future challenges," Energy and Buildings, vol. 107, pp. 264-278, 2015.

700 [20] O. G. Santin, L. Itard, and H. Visscher, "The effect of occupancy and building characteristics 701 on energy use for space and water heating in Dutch residential stock," Energy and buildings, vol. 702 41, no. 11, pp. 1223-1232, 2009.

703 [21] V. Cheng and K. Steemers, "Modelling domestic energy consumption at district scale: A tool 704 to support national and local energy policies," Environmental Modelling \& Software, vol. 26, no. 705 10, pp. 1186-1198, 2011.

706 [22] H. Yang, B. H. Yan, C. Sun, and G. Q. Xia, "Study on the Behavior Energy-Saving of the Heat 707 Users of Central Heating System," in Advanced Materials Research, 2013, vol. 608, pp. 1194708 1197: Trans Tech Publ.

709 [23] G. Nair, L. Gustavsson, and K. Mahapatra, "Factors influencing energy efficiency investments 710 in existing Swedish residential buildings," Energy Policy, vol. 38, no. 6, pp. 2956-2963, 2010.

711 [24] J. K. Day and D. E. Gunderson, "Understanding high performance buildings: The link between 712 occupant knowledge of passive design systems, corresponding behaviors, occupant comfort and 713 environmental satisfaction," Building and Environment, vol. 84, pp. 114-124, 2015.

714 [25] S. Guo, D. Yan, C. Peng, Y. Cui, X. Zhou, and S. Hu, "Investigation and analyses of residential 715 heating in the HSCW climate zone of China: Status quo and key features," Building and 716 Environment, vol. 94, pp. 532-542, 2015.

717 [26] S. D’Oca, V. Fabi, S. P. Corgnati, and R. K. Andersen, "Effect of thermostat and window 718 opening occupant behavior models on energy use in homes," Building Simulation, vol. 7, no. 6, pp. 719 683-694, 2014. 
[27] R. Fritsch, A. Kohler, M. Nygård-Ferguson, and J.-L. Scartezzini, "A stochastic model of user 721 behaviour regarding ventilation," Building and Environment, vol. 25, no. 2, pp. 173-181, 1990.

722 [28] G. Y. Yun, J. Choi, and J. T. Kim, "Energy performance of direct expansion air handling unit 723 in office buildings," Energy and Buildings, vol. 77, pp. 425-431, 2014.

724 [29] Y. Wang, J. Kuckelkorn, F.-Y. Zhao, D. Liu, A. Kirschbaum, and J.-L. Zhang, "Evaluation on 725 classroom thermal comfort and energy performance of passive school building by optimizing 726 HVAC control systems," Building and Environment, vol. 89, pp. 86-106, 2015.

727 [30] J. Ouyang and K. Hokao, "Energy-saving potential by improving occupants' behavior in urban 728 residential sector in Hangzhou City, China," Energy and buildings, vol. 41, no. 7, pp. 711-720, 7292009.

730 [31] Y. Cui, D. Yan, and C.-f. Chen, "Exploring the factors and motivations influencing heating 731 behavioral patterns and future energy use intentions in the hot summer and cold winter climate zone 732 of China," Energy and Buildings, vol. 153, pp. 99-110, 2017.

733 [32] V. Fabi, R. V. Andersen, S. Corgnati, and B. W. Olesen, "Occupants' window opening 734 behaviour: A literature review of factors influencing occupant behaviour and models," Building 735 and Environment, vol. 58, pp. 188-198, 2012.

736 [33] T. Hong, D. Yan, S. D'Oca, and C.-f. Chen, "Ten questions concerning occupant behavior in 737 buildings: The big picture," Building and Environment, vol. 114, pp. 518-530, 2017.

738 [34] H. Yoshino et al., "Indoor thermal environment of urban residential buildings in China: winter 739 investigation in five major cities," Energy and buildings, vol. 36, no. 12, pp. 1227-1233, 2004.

740 [35] C. Peng, D. Yan, R. Wu, C. Wang, X. Zhou, and Y. Jiang, "Quantitative description and 741 simulation of human behavior in residential buildings," Building Simulation, vol. 5, no. 2, pp. 85$74294,2011$.

743 [36] J. Ge, J. Wu, S. Chen, and J. Wu, "Energy efficiency optimization strategies for university 744 research buildings with hot summer and cold winter climate of China based on the adaptive thermal 745 comfort," Journal of Building Engineering, vol. 18, pp. 321-330, 2018.

746 [37] S. Chen, N. Li, J. Guan, Y. Xie, F. Sun, and J. Ni, "A statistical method to investigate national 747 energy consumption in the residential building sector of China," Energy and Buildings, vol. 40, no. 748 4, pp. 654-665, 2008.

749 [38] C. A. Moser and G. Kalton, Survey methods in social investigation. Routledge, 2017.

750 [39] Ministry of Housing and Urban-Rural Development of the People's Republic of China, "GB 751 50736-2012, Design code for heating ventilation and air conditioning of civil buildings," ed. 752 Beijing: MOHURD, 2012.

753 [40] C. Liu et al., "High resolution mapping of overheating and mortality risk," vol. 122, pp. 1-14, 7542017. 
755 [41] R. V. Krejcie and D. W. Morgan, "Determining sample size for research activities," 756 Educational and psychological measurement, vol. 30, no. 3, pp. 607-610, 1970.

757 [42] A. N. Oppenheim, Questionnaire design, interviewing and attitude measurement. Bloomsbury 758 Publishing, 2000.

759 [43] P. Hoes, J. Hensen, M. Loomans, B. De Vries, and D. Bourgeois, "User behavior in whole 760 building simulation," Energy and buildings, vol. 41, no. 3, pp. 295-302, 2009.

761 [44] H. Liu, Y. Wu, B. Li, Y. Cheng, and R. Yao, "Seasonal variation of thermal sensations in 762 residential buildings in the Hot Summer and Cold Winter zone of China," Energy and Buildings, 763 vol. 140, pp. 9-18, 2017.

764 [45] N. H. Nie, D. H. Bent, and C. H. Hull, SPSS: Statistical package for the social sciences. 765 McGraw-Hill New York, 1975.

766 [46] C. Kothari, "Research Methodology methods and techniques second edition," ed: New Age, 7672017.

768 [47] M. Shipworth, "Thermostat settings in English houses: No evidence of change between 1984 769 and 2007," Building and Environment, vol. 46, no. 3, pp. 635-642, 2011.

770 [48] J. An, D. Yan, and T. Hong, "Clustering and statistical analyses of air-conditioning intensity 771 and use patterns in residential buildings," Energy and Buildings, vol. 174, pp. 214-227, 2018.

772 [49] ASHRAE, "ASHRAE Standard 55, thermal environmental conditions for human occupancy,," 773 Atlanta: American Society of Heating, Refrigerating and Air-Conditioning Engineers Inc, Atlanta, 7742013.

775 [50] T. Huo, H. Ren, and W. Cai, "Estimating urban residential building-related energy 776 consumption and energy intensity in China based on improved building stock turnover model," Sci 777 Total Environ, vol. 650, no. Pt 1, pp. 427-437, Feb 102019.

778 [51] China Association of Building Energy Efficiency. Research Report of China Building Energy 779 Consumption 2016 [Online]. Available: http://www.efchina.org/Attachments/Report/report$780 \quad$ 20170710-1/report-20170710-1

781 [52] J. Yi, Concept Debate for China's Building Energy Conservation. Beijing: China 782 Architecture\& Building Press, 2016. 
785 Questionnaire contents

786 Part 1: Questions of Basic information of respondents and buildings

787 Questions of Basic building information

788 Q1: Family structure (single choice):

789 Single

790 Couple

791 Couple with a Child

$792 \bigcirc$ Couple with Child and the elderly

793 O Others

794

795 Q2: Home time (multiple choice):

$796 \square$ Morning (7:00-12:00)

$797 \square$ Noon (12:00-14:00)

$798 \square$ Afternoon (14:00-18:00)

$799 \square$ Evening (18:00-7:00)

800

801 Q3: Dwelling structure (single choice):

$802 \bigcirc$ One bedroom 
$803 \bigcirc$ Two bedrooms

$804 \bigcirc$ Three bedrooms

$805 \bigcirc$ Four bedrooms

806 Others _

807 Part 2: Questions of Heating behaviors

808 (*the following behaviors were limited to weekdays)

809 Section 1. Questions for Bedroom

810 Q4: Whether or not you heat your bedroom? 【if not, please skip 】

$811 \bigcirc$ Not at all

$812 \bigcirc$ If Yes, please tick the box that is relevant to your heating measures:

$813 \square$ Air conditioning, temperature, with setting-point $\_\_{ }^{\circ} \mathrm{C}^{*}$

$814 \square$ Underfloor heating, with

815 temperature setting-point___ ${ }^{\circ} \mathrm{C}$ when room occupied*;

816 temperature setting-point___ ${ }^{\circ} \mathrm{C}$ when nobody at home*;

817 (If you turn off underfloor heating when nobody is in the bedroom please write "0")

$818 \quad$ (multiple choice)

$819 \square$ Oil heater

$820 \square$ Heating radiator

$821 \square$ Infrared heating 
$822 \square$ Fan heater

$823 \square$ Electric blanket

$824 \square$ Other $\square$ *

825

826 Q5: What is the status of door or window in your bedroom when heating is in

827 operation? (single choice)

$828 \bigcirc$ Closed

$829 \bigcirc$ Open with a small gap

$830 \bigcirc$ Open with a big gap

831

832 Q6: How do you set the air-conditioning operation mode? (single choice)

$833 \bigcirc$ Sleep mode

$834 \bigcirc$ Keep on until next day

$835 \bigcirc$ Setting time shutdown (how many hours) *

$836 \bigcirc$ Don’t operate air conditioning

$837 \bigcirc$ Other

838

839 
840 Section 2. Questions for Living Room (contains the study)

841 Q7: Do you heat your living room? 【if not, please skip 】

$842 \bigcirc$ Not at all

843 Yes; Please tick the box that is relevant to your heating measures:

$844 \square$ air conditioning, setting-point was__ $\_{ }^{\circ} \mathrm{C}^{*}$

$845 \square$ underfloor heating,

846 temperature set point ${ }^{\circ} \mathrm{C}$ when room occupied*

847 temperature set point ${ }^{\circ} \mathrm{C}$ when nobody at home*

848 (If you turn off underfloor heating when nobody is in the living room please write "0")

$849 \quad$ (multiple choice)

$850 \square$ Oil heater

$851 \square$ Heating radiator

$852 \square$ Infrared heating

$853 \square$ Fan heater

$854 \square$ Electric blanket

$855 \square$ Other

856

857 Q8: Your family members' clothing adjustment behaviors: (single choice)

$858 \bigcirc$ Adding clothes to reduce heating dependence

$859 \bigcirc$ Relying on heating rather than clothing adjustment 
861 Q9: The usual status of doors or windows in your living room when occupier

862 heating is 'On': (single choice)

$863 \bigcirc$ Closed

$864 \bigcirc$ Open with a small gap

$865 \bigcirc$ Open with a big gap

866

867 Q10: Occasions of air condition usage in the living room: (single choice)

868 (If heating mode doesn't include air conditioning, this question can be skipped)

$869 \bigcirc$ Use air conditioning as long as occasion room occupied

$870 \bigcirc$ Use air conditioning when feeling cold

872 Q11: Habits of air condition usage in the living room: (single choice)

873 (If heating mode doesn't include air conditioning, this question can be skipped)

$874 \bigcirc$ Set a high temperature for rapid warming, then lower it when room heats up

$875 \bigcirc$ Set constant temperature

876 O Other__ * 
879 Section 3. Questions for Fresh Air

880 Q12: The usual status of doors or windows in your bedroom when no heating:

$881 \quad$ (single choice)

$882 \bigcirc$ Closed

$883 \bigcirc$ Open with a small gap

$884 \bigcirc$ Open with a big gap

885

886 Q13: Your family members' habits of window operation: (single choice)

$887 \square$ Ventilation based on the weather

$888 \square$ Ventilation based on indoor air quality

$889 \square$ Ventilation based on daily habits

890

891 